\title{
Direct simulation of transitional plane fountains in a homogeneous fluid
}

\author{
Wenxian $\operatorname{Lin}^{1} \quad$ S. W. Armfield ${ }^{2} \quad$ J. C. Patterson ${ }^{3}$
}

(Received 31 August 2006; revised 22 December 2007)

\begin{abstract}
The fluid dynamics of transitional plane fountains with the Froude and Reynolds numbers in the ranges $1 \leq \mathrm{Fr} \leq 6$ and $100 \leq \operatorname{Re} \leq 800$ is investigated to examine the entrainment associated with the onset of turbulence. The direct numerical simulation results show that negligible entrainment occurs at the upflow-downflow interface for small $\mathrm{Fr}$ $(<2)$ fountains, and only small entrainment on the downflow-ambient interface. However, entrainment occurs at both the upflow-downflow and the downflow-ambient interfaces for large $\operatorname{Fr}(>2)$ fountains, even at $\operatorname{Re}=100$, with the extent of the entrainment increasing almost linearly with Re. The upflow and fountain widths show strong Re dependence and increase linearly with Fr, demonstrating that the onset of entrainment and instability occurs at relatively high $\operatorname{Re}(>1000)$ in small $\operatorname{Fr}(\leq 2)$ fountains, but at small $\operatorname{Re}(<100)$ in large $\operatorname{Fr}(>2)$ fountains.
\end{abstract}

See http://anziamj.austms.org.au/ojs/index.php/ANZIAMJ/article/view/127 for this article, (c) Austral. Mathematical Soc. 2007. Published December 27, 2007. ISSN $1446-8735$ 


\section{Contents}

1 Introduction

C693

2 Numerical methods

C695

3 Results and discussions

C696

$3.1 \mathrm{Fr}=2$ fountains . . . . . . . . . . . . . . . C698

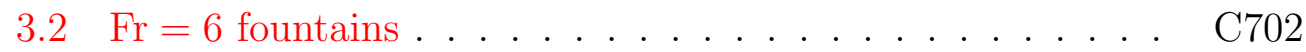

3.3 Time averaged features . . . . . . . . . . . . . C702

4 Conclusions

C705

References

C706

\section{Introduction}

Fountain flows occur frequently in heat transfer and environmental settings. In any process where a dense fluid is steadily injected upward into a miscible and less dense fluid, or in the reverse case when lighter fluid is injected downward into a denser ambient fluid, a fountain-type structure forms. One particular application of fountain flows is in the heating and ventilation of buildings via downward facing jets located at the ceiling. An improved understanding of the behavior of fountain flows is of fundamental interest to fluid mechanics and heat transfer.

Extensive studies have been carried out on turbulent fountains with high values of $\operatorname{Fr}(\gg 1)$ and $\operatorname{Re}(\geq 800)[1,2,3,4$, for example ], where Fr and Re are the Froude number and Reynolds number, defined as,

$$
\mathrm{Fr}=\frac{V_{0}}{\left(X_{0} \sigma_{0}\right)^{1 / 2}}, \quad \operatorname{Re}=\frac{V_{0} X_{0}}{\nu},
$$


in which $V_{0}, X_{0}, \sigma_{0}, \nu$ are, respectively the discharge velocity, the source radius (for round fountains) or the source half-width (for plane fountains), reduced gravity between the fountain and the ambient fluid, and kinematic viscosity of the fluid. For weak fountains, the influence of the discharge momentum is equal to or less than that of the negative buoyancy and the fountain penetration height is of the same order of $X_{0}$. The fountain is then characterized by small values of $\operatorname{Fr}(\leq 1.0)$ and $\operatorname{Re}(\leq 500)$. Such fountains have no distinguishable upward and downward flows, instead the streamlines curve and spread from the source. The recent analytical and numerical studies of Lin and Armfield $[5,6,7]$ and Philippe et al. [8] show that weak fountains demonstrate different behavior to turbulent fountains.

Nevertheless, the understanding of fountains in transition to turbulence with intermediate Fr and $\operatorname{Re}(\mathrm{Fr}>1$ but not $\gg 1, \operatorname{Re}>100$ but not $\gg 100)$ is currently lacking. However, it is in this transitional flow regime the onset of instability and turbulence occurs. Furthermore, many fountains of practical interest operate in this transitional flow regime. For example, a typical stack driven, single sided, ventilation has an Re at and above 1000 and when its Fr approaches about 10 the air flow will transit from laminar to turbulent state [9]. It is therefore of profound fundamental and engineering significance and social and environmental benefits to develop a thorough understanding of the dynamics and structure of fountains in transition to turbulence.

We investigate the transient behavior of unsteady transitional plane fountains in quiescent homogeneous ambient with intermediate values of $1 \leq \mathrm{Fr} \leq$ 6 and $100 \leq \mathrm{Re} \leq 800$ (in the Fr $=1$ case, the upper limit of Re is extended to 2000) by direct numerical simulation (DNS). In Section 2, the governing equations and numerical methods are briefly described. The DNs results are presented and discussed in Section 3. Section 4 concludes. 


\section{Numerical methods}

The physical system under consideration is a rectangular tank containing a Newtonian fluid initially at rest and at temperature $T_{a}$, the sidewalls are non-slip and insulated and the top is open. On the bottom center, a slot with width $2 X_{0}$ is used as the fountain discharge source. The remaining bottom region is a rigid non-slip insulated boundary. At time $t=0$, a stream of fluid at $T=T_{0}<T_{a}$ is injected impulsively into the container from the source to initiate the fountain and this discharge is maintained thereafter. Due to the symmetry of the system geometry and the boundary and initial conditions, the fountain flow is assumed to be laminar and symmetric about the slot center.

The flow is described in non-dimensional form by the following NavierStokes and temperature equations with the Boussinesq assumption,

$$
\begin{aligned}
& \frac{\partial u}{\partial x}+\frac{\partial v}{\partial y}=0 \\
& \frac{\partial u}{\partial \tau}+u \frac{\partial u}{\partial x}+v \frac{\partial u}{\partial y}=-\frac{\partial p}{\partial x}+\frac{1}{\operatorname{Re}}\left(\frac{\partial^{2} u}{\partial x^{2}}+\frac{\partial^{2} u}{\partial y^{2}}\right), \\
& \frac{\partial v}{\partial \tau}+u \frac{\partial v}{\partial x}+v \frac{\partial v}{\partial y}=-\frac{\partial p}{\partial y}+\frac{1}{\operatorname{Re}}\left(\frac{\partial^{2} v}{\partial x^{2}}+\frac{\partial^{2} v}{\partial y^{2}}\right)+\frac{1}{\operatorname{Fr}^{2}} \theta \\
& \frac{\partial \theta}{\partial \tau}+u \frac{\partial \theta}{\partial x}+v \frac{\partial \theta}{\partial y}=\frac{1}{\operatorname{RePr}}\left(\frac{\partial^{2} \theta}{\partial x^{2}}+\frac{\partial^{2} \theta}{\partial y^{2}}\right)
\end{aligned}
$$

where $\operatorname{Pr}$ is the Prandtl number. In these equations all lengths, velocities, time, pressure, and temperatures are made dimensionless by $X_{0}, V_{0}, X_{0} / V_{0}$, $\rho V_{0}^{2},\left(T_{0}-T_{a}\right)$, respectively, where $\rho$ is the fluid density.

The DNs has been carried out using a finite volume method. The governing equations are discretized on a non-staggered mesh, with standard second order central differences used for the viscous, pressure gradient, and divergence terms, whereas the QUICK third order upwind scheme is used for the 
advective terms. The momentum and temperature equations are solved using an ADI scheme. The second order Adams-Bashforth scheme and CrankNicolson scheme are used for the time integration of the advective terms and the diffusive terms, respectively. To enforce the continuity, the pressure correction method is used to construct a Poisson equation, which is solved using the preconditioned generalized minimum residual (GMRES) method. A nonuniform mesh of $399 \times 397$ grid points has been used in this study to enable the regions of rapid solution variation to be accurately resolved while limiting the total number of nodes. Lin and Armfield [5] gave detailed descriptions of these schemes, and the code has been successfully used for the simulation of a range of buoyancy dominated flows.

\section{Results and discussions}

To show the effects of Fr and Re on the onset of entrainment in fountain flows, a series of DNS have been carried out for plane fountains in quiescent homogeneous fluids with selected values of Fr and Re. Specifically, the Fr $=1$ fountains at $\operatorname{Re}=500,1000,1500$, and 2000 , the $\mathrm{Fr}=2$ fountains and the $\mathrm{Fr}=6$ fountains, both at $\operatorname{Re}=100,200,300,500$, and 800 , have been chosen to show the effect of Re on small, medium, and large Fr fountains, respectively. As the effect of $\operatorname{Pr}$ is not included in this study, a fixed $\operatorname{Pr}=7$ of water has been used in all simulations.

The predominant parameters characterizing the transient fountain behavior are the dimensionless maximum fountain penetration height $y_{m}$ as defined in Figure 1, the upflow width $x_{u}$, and the fountain width $x_{w} . x_{u}$ and $x_{w}$, both made dimensionless by $X_{0}$, denote respectively the location of the upflowdownflow interface at which the vertical velocity of fluid becomes zero, and the location of the downflow-ambient interface where the fluid temperature is $1 \%$ of the temperature difference between the jet fluid at the source and the ambient fluid. Figure 1 depicts the definitions of these parameters, where 
Low Re Fountain

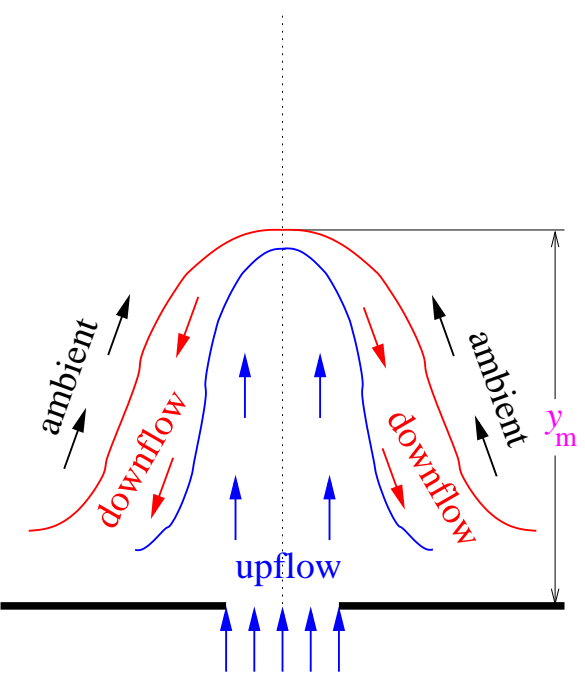

High Re Fountain

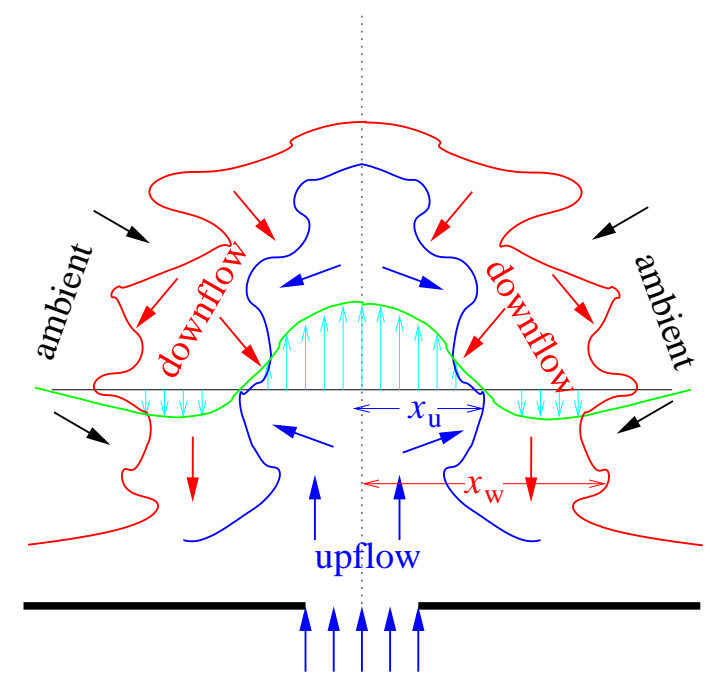

FiguRE 1: Schematic of typical vertical profiles of $x_{u}$ and $x_{w}$ for a low Re fountain (left) and a high Re fountain (right) at steady state and the definitions of $y_{m}, x_{u}$ and $x_{w}$. 
typical steady state vertical profiles of $x_{u}$ and $x_{w}$ are sketched for low Re and high Re fountains respectively.

The additional important parameters characterizing the transient fountain behavior are $E_{u}(y)$ and $E_{w}(y)$, which are the entrainment at height $y$ on the upflow-downflow interface (at $x_{u}$ ) and on the downflow-ambient interface $\left(\right.$ at $\left.x_{w}\right)$, respectively, defined as [10],

$$
E_{u}(y)=\frac{\int_{0}^{X_{u}} T(Y) d X / X_{u}-T_{0}}{T_{a}-T_{0}}, \quad E_{w}(y)=\frac{\int_{0}^{X_{w}} T(Y) d X / X_{w}-T_{0}}{T_{a}-T_{0}},
$$

where $X_{u}$ and $X_{w}$ are the dimensional form of $x_{u}$ and $x_{w}$ respectively, and $Y$ is the dimensional height.

\section{1 $\mathrm{Fr}=2$ fountains}

Figures 2 and 3 present the evolution of temperature contours and the steady state profiles of $x_{u}, x_{w}, E_{u}$ and $E_{w}$ for the $\mathrm{Fr}=2$ fountain at $\mathrm{Re}=200,500$ and 800. These figures show that Re has a large effect on $x_{u}, x_{w}, E_{u}$ and $E_{w}$ of the $\mathrm{Fr}=2$ fountain, especially when $\operatorname{Re} \geq 500$, as at such high Re entrainment is present at the interfaces of the upflow-downflow, the downflowambient and the intrusion-ambient, and the extent of the entrainment increases with Re. The results also show that $E_{u} \ll E_{w}$ and $x_{u}<x_{w}$ for these $\operatorname{Fr}=2$ fountains. Furthermore, the DNS results show that both $E_{u}$ and $E_{w}$ have relatively small values for the $\mathrm{Fr}=2$ fountains. Similar flow dynamics are also found for the $\mathrm{Fr}=1$ fountains, although the onset of entrainment occurs at much higher $\operatorname{Re}($ at $\operatorname{Re}>1000$ ), indicating that entrainment is weak or negligible in these small Fr fountains, especially at low Re. 

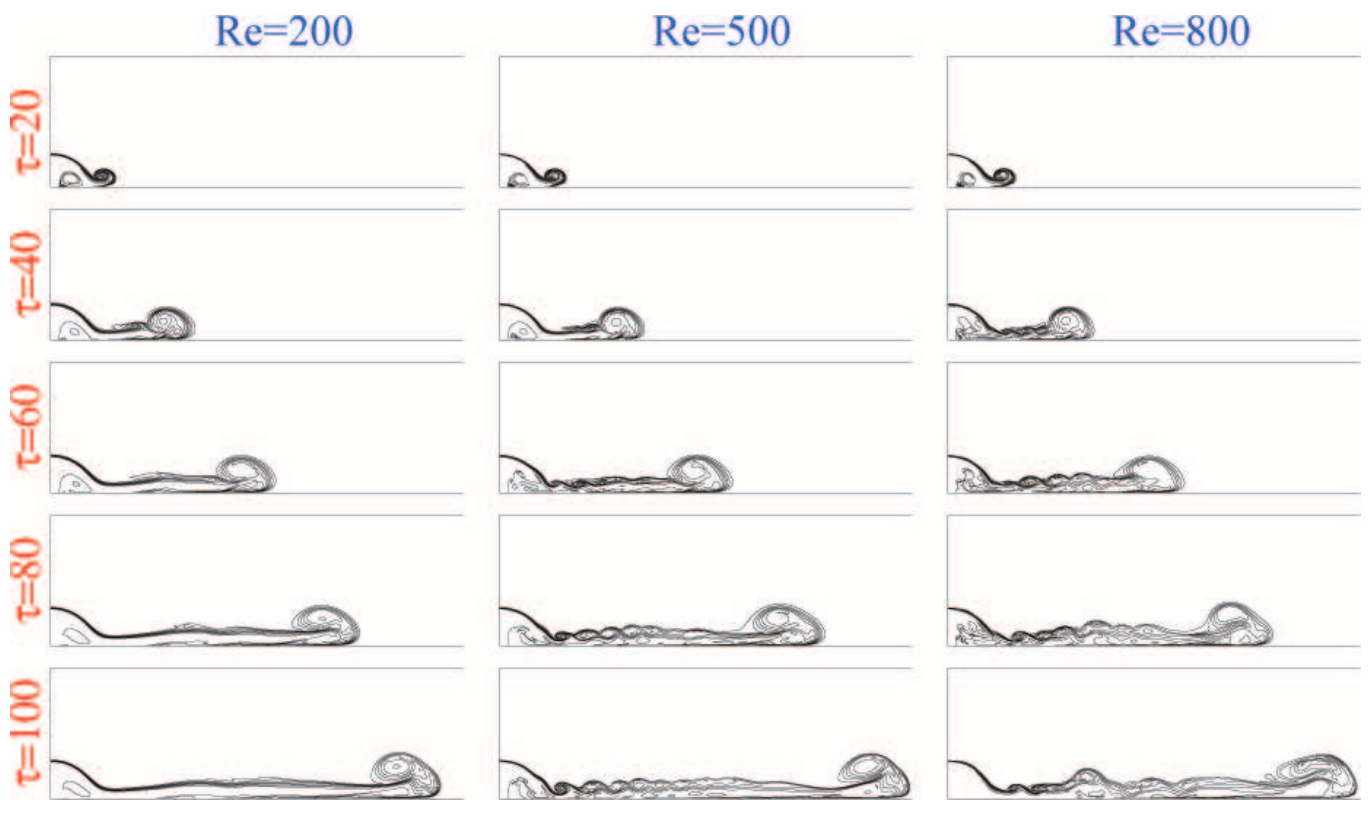

Figure 2: The temperature contours for the $\mathrm{Fr}=2$ fountains at times $\tau=20,40,60,80$ and 100 and at $\operatorname{Re}=200,500$ and 800 . 

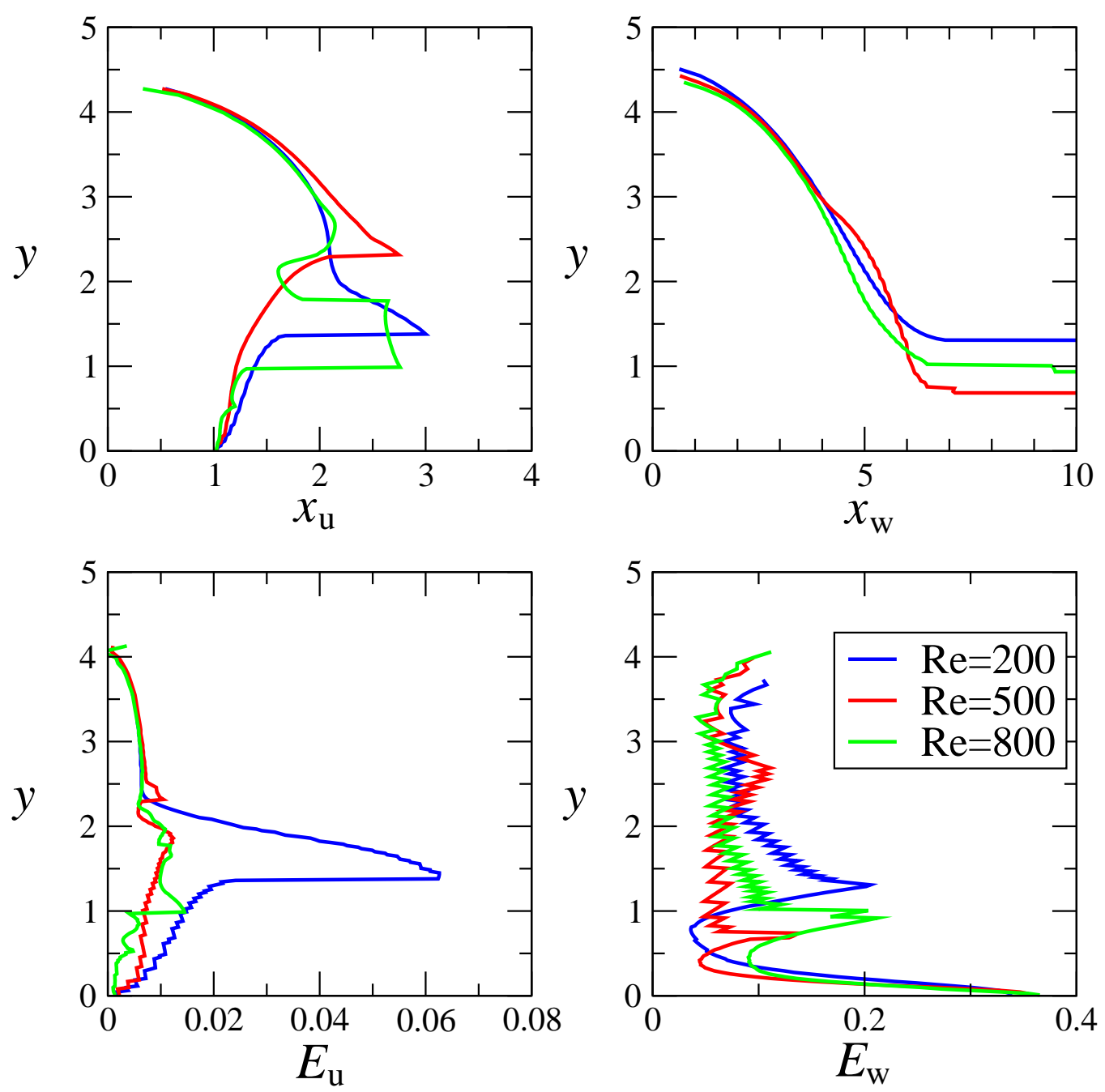

Figure 3: The steady state profiles of $x_{u}, x_{w}, E_{u}$ and $E_{w}$ of the $\mathrm{Fr}=2$ fountains at $\mathrm{Re}=200,500$ and 800 . 


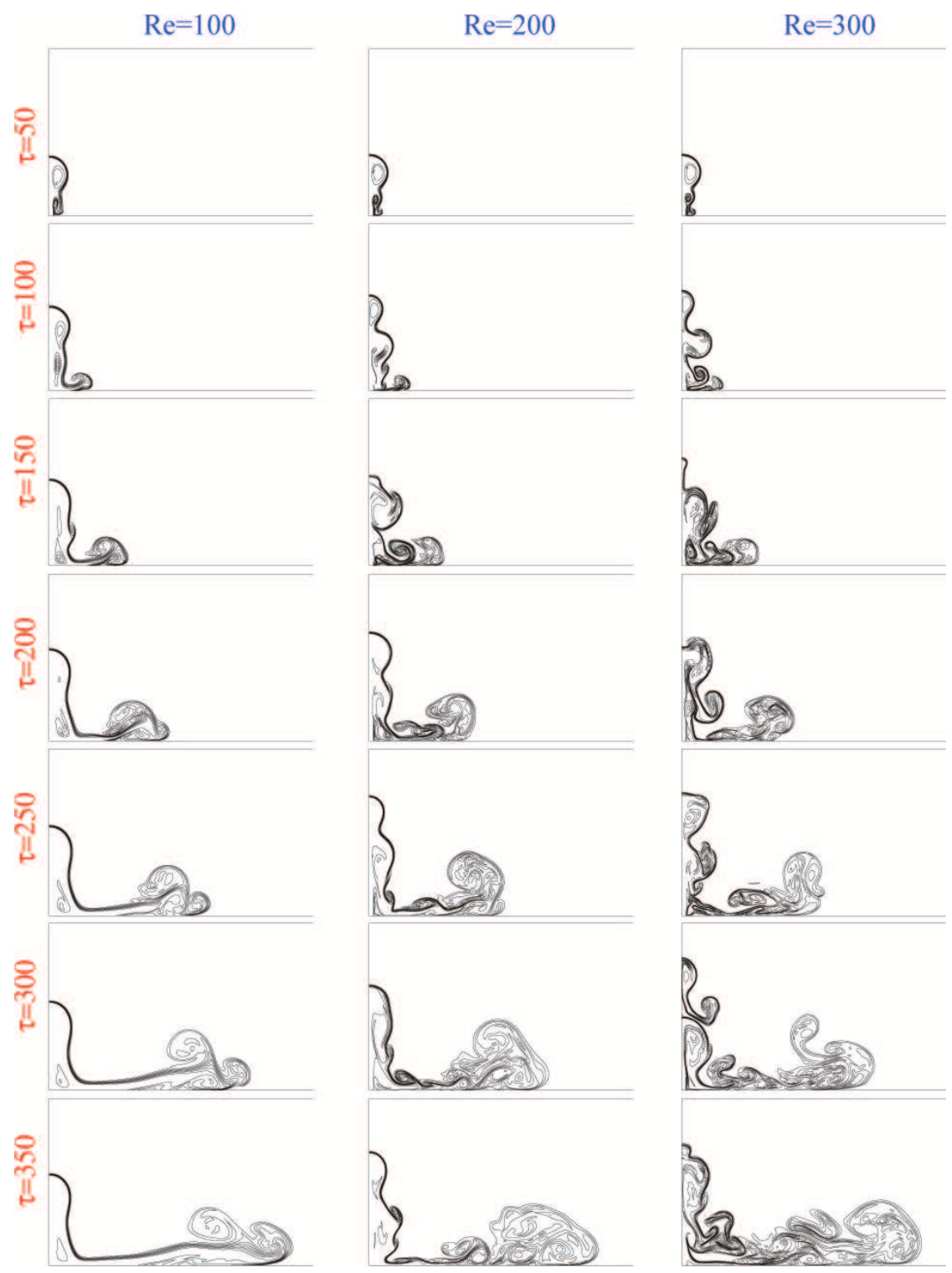

Figure 4: The temperature contours of the $\mathrm{Fr}=6$ fountains at times $\tau=$ $50,100,150,200,250$, and 350 and at $\mathrm{Re}=100,200$ and 300 . 


\section{$3.2 \mathrm{Fr}=6$ fountains}

Figures 4 and 5 present the evolution of the temperature contours and the fully developed profiles of $x_{u}, x_{w}, E_{u}$ and $E_{w}$ for the $\mathrm{Fr}=6$ fountain at $\operatorname{Re}=$ 100,200 and 300. From these figures, it is apparent that Re has a substantial effect on $x_{u}, x_{w}, E_{u}$ and $E_{w}$ for the $\mathrm{Fr}=6$ fountain. Unlike the small $\mathrm{Fr}$ fountains (when Fr $\leq 2$, as shown above), these large Fr fountains have entrainment present at the interfaces of the upflow-downflow, the downflowambient and the intrusion-ambient at Re as small as 100, and the extent of entrainment increases dramatically with Re. Although $E_{u}$ is found to be quite small with respect to $E_{w}$, both are quite large, especially compared to the small Fr fountains. The time series of the $\mathrm{Fr}=6$ fountains presented in Figure 6 show that significant fluctuations are observed for the $\mathrm{Fr}=6$ fountains, especially when Re is large, giving further evidence that the onset of entrainment and instability in large Fr fountains occurs at quite small Re and the extent of entrainment increases dramatically with Re.

\subsection{Time averaged features}

Figure 7 presents the time averaged DNS results of $x_{u}, x_{w}, E_{u}$ and $E_{w}$ of the $\mathrm{Fr}=1$ fountains, $\mathrm{Fr}=2$ fountains and $\mathrm{Fr}=6$ fountains at various Re considered. It shows that for small Fr fountains (when $\mathrm{Fr} \leq 2$ ), $E_{u}$ is essentially negligible, indicating that there is little entrainment and mixing between the upflow and the downflow, although there is non-trivial entrainment on the downflow-ambient interface which has very weak dependence on Re. It also shows that both $x_{u}$ and $x_{w}$ are essentially independent of Re for these small Fr fountains. Nevertheless, the $\mathrm{Fr}=6$ fountains have quite different flow features, with strong entrainment occurring at both the upflow-downflow interface and the downflow-ambient interface and the values of $E_{u}$ and $E_{w}$ increasing dramatically, almost linearly, with Re. The onset of entrainment in these large Fr fountains occurs at quite small Re, with even at $\operatorname{Re}=100$ 

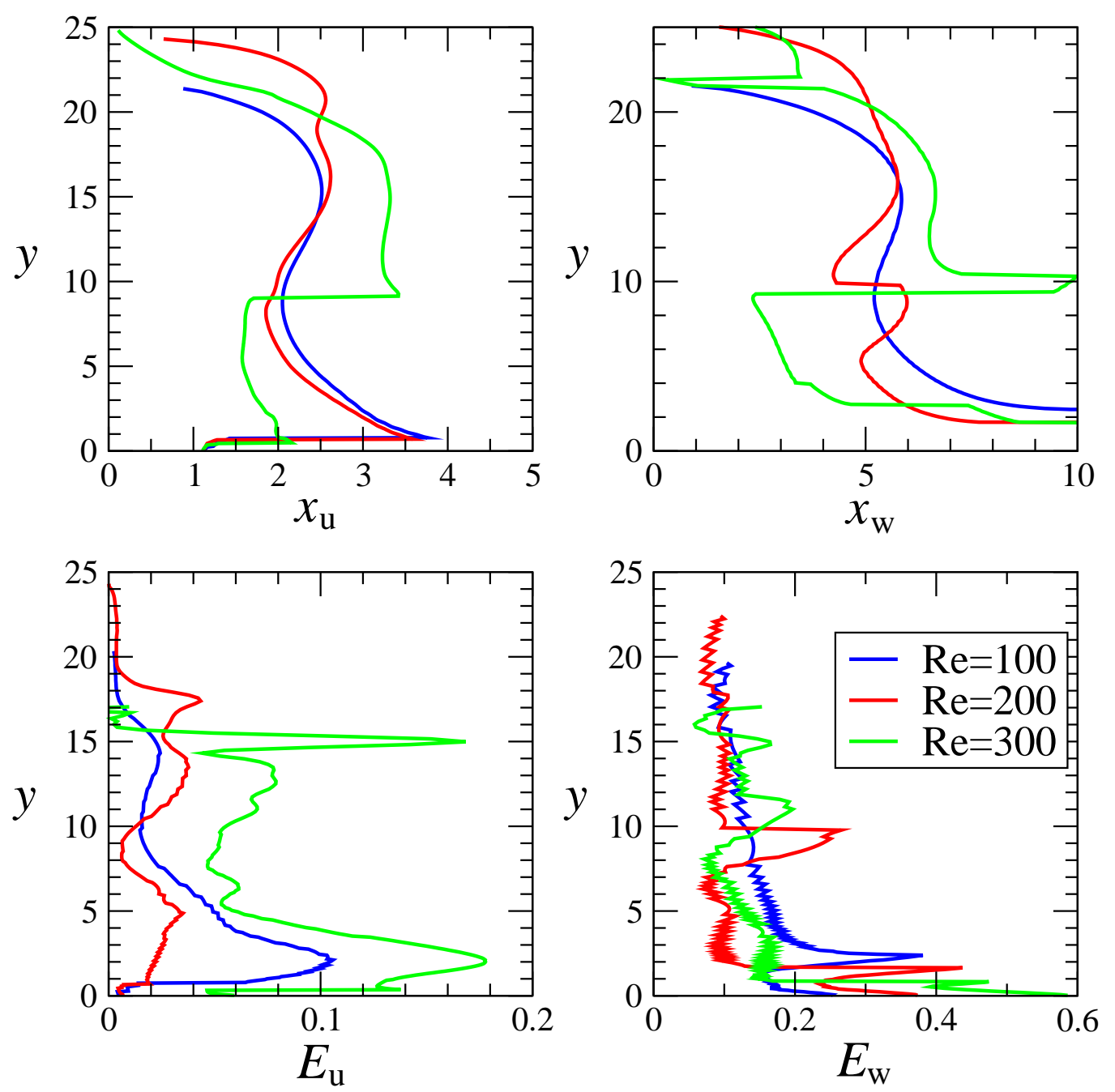

Figure 5: The steady state profiles of $x_{u}, x_{w}, E_{u}$ and $E_{w}$ of the $\mathrm{Fr}=6$ fountains at $\mathrm{Re}=100,200$ and 300 . 

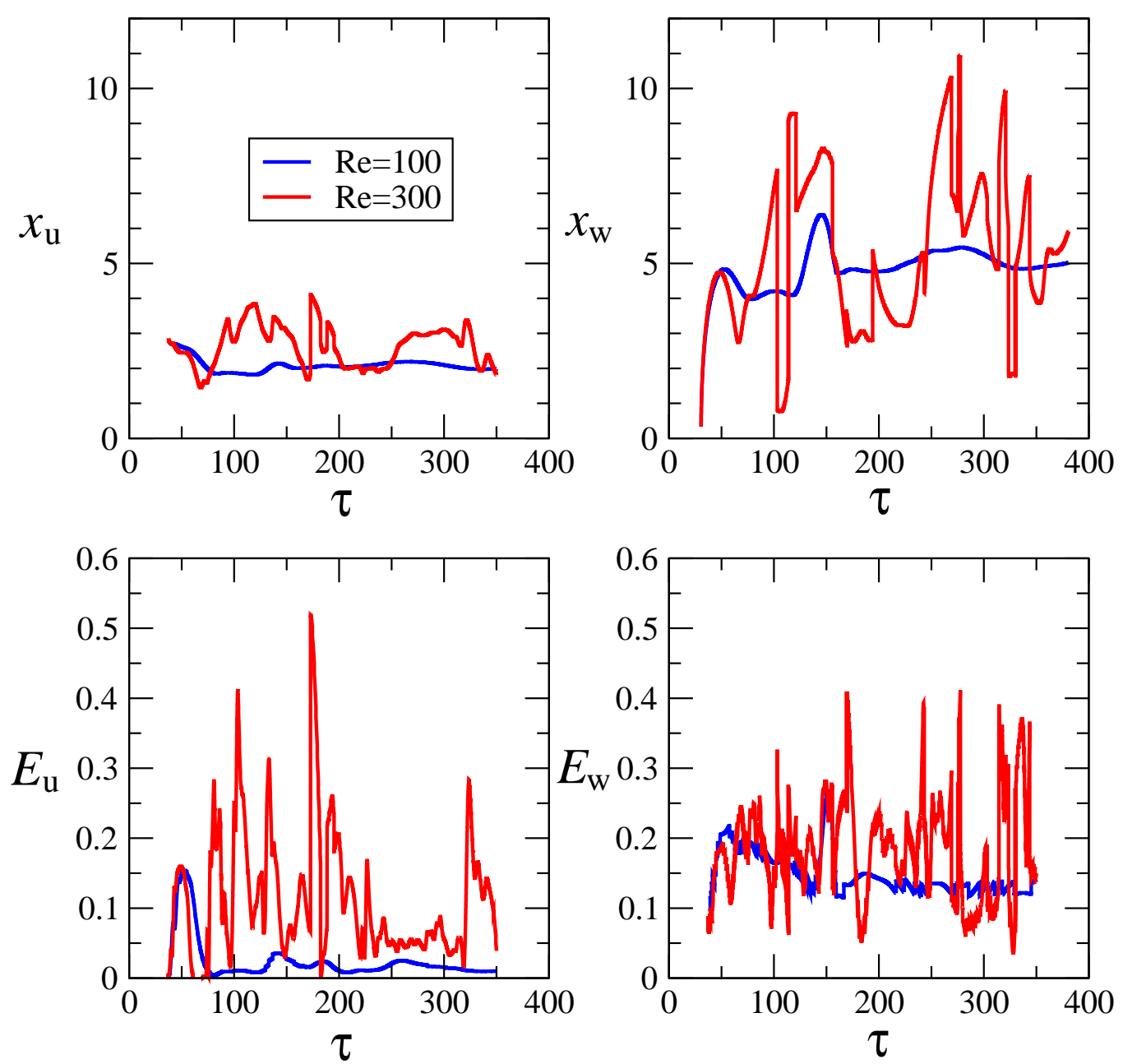

Figure 6: The time series of $x_{u}, x_{w}, E_{u}$ and $E_{w}$ of the $\operatorname{Fr}=6$ fountains at $\mathrm{Re}=100$ and 300 . 

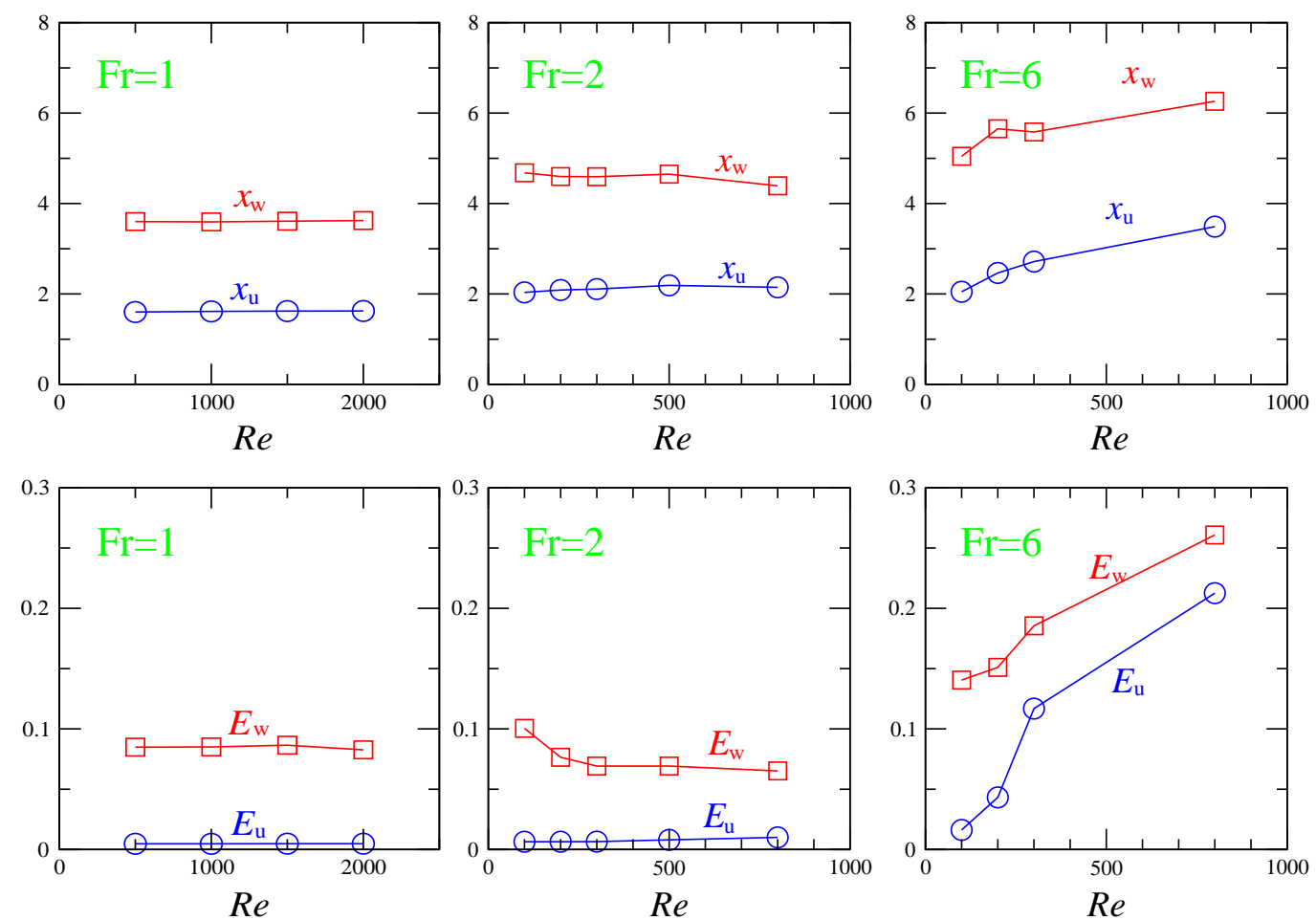

Figure 7: The time averaged values of $x_{u}, x_{w}, E_{u}$ and $E_{w}$ at steady state plotted against Re.

some entrainment observed. The values of $x_{u}$ and $x_{w}$ are also found to increase, almost linearly, with Re, indicating the extent of the entrainments and the mixing increases dramatically with Re, as noted above.

\section{Conclusions}

For small Fr fountains $(\mathrm{Fr} \leq 2)$, there is little mixing and entrainment at the upflow-downflow interface, and the entrainment on the downflow-ambient 
interface, although occurring, is also quite small. The upflow and fountain widths show no Re dependence but slightly increase with Fr. For large Fr fountains $(\mathrm{Fr}>2)$, however, entrainment occurs at both the upflow-downflow interface and the downflow-ambient interface, even for Re as low as 100. The extents of the entrainment increases almost linearly with Re. The upflow and fountain widths show strong Re dependence and increase almost linearly with Fr. The onset of entrainment and instability occurs at relatively high Re $(>1000)$ in small $\mathrm{Fr}(\leq 2)$ fountains, but at small $\operatorname{Re}(<100)$ in large $\mathrm{Fr}$ $(>2)$ fountains. The quantitative dependence of the onset of entrainment and instability on Fr and Re can be, and should be, sought with much wider ranges of Re and Fr and with three dimensional DNS in the future work.

Acknowledgements: The authors acknowledge the support of the Australian Research Council. W. Lin also acknowledges the support from the 973 Program (2007CB216405), the Natural Science Foundation of Yunnan Province (Key Projects 2003E0004Z), the New Century Excellent Talents Program in University of China (NCET-04-0918), the National Natural Science Foundation of China (10262003), and the JCU Faculty Grant Scheme.

\section{References}

[1] B. R. Morton. Forced plumes. J. Fluid Mech., 5, 1959, 151-163. doi:10.1017/S002211205900012X C693

[2] J. S. Turner. Jets and plumes with negative or reversing buoyancy. J. Fluid Mech., 26, 1966, 779-792. doi:10.1017/S0022112066001526 C693

[3] W. D. Baines, J. S. Turner and I. H. Campbell. Turbulent fountains in an open chamber. J. Fluid Mech., 212, 1990, 557-592. doi:10.1017/S0022112090002099 C693 
[4] L. J. Bloomfield and R. C. Kerr. A theoretical model of a turbulent fountain. J. Fluid Mech., 424, 2000, 97-216. doi:10.1017/S0022112000001907 C693

[5] W. Lin and S. W. Armfield. Direct simulation of weak axisymmetric fountains in a homogeneous fluid. J. Fluid Mech., 403, 2000, 67-88. doi:10.1017/S0022112099006953 C694, C696

[6] W. Lin and S. W. Armfield. Weak fountains in a stratified fluid. Phys. Rev. E, 66, 2002, 066308. doi:10.1103/PhysRevE.66.066308 C694

[7] W. Lin and S. W. Armfield. The Reynolds and Prandtl number dependence of weak fountains. Computational Mechanics, 31, 2003, 379-389. doi:10.1007/s00466-003-0440-5 C694

[8] P. Philippe, C. Raufaste, P. Kurowski and P. Petitjeans. Penetratioon of negatively buoyant jet in a miscible liquid. Phys. Fluids, 17, 2005, 053601. doi:10.1063/1.1907735 C694

[9] P. F. Linden. The fluid mechanics of natural ventilation. Annu. Rev. Fluid Mech., 31, 1999, 201-238. doi:10.1146/annurev.fluid.31.1.201 C694

[10] P. Bhattacharjee and E. Loth. Entrainment by a refrigerated air curtain down a wall. ASME J. Fluids Eng., 126: 871-879, 2004. doi:10.1115/1.1792263 C698 


\section{Author addresses}

1. Wenxian Lin, School of Engineering, James Cook University, Townsville, Australia; Solar Energy Research Institute, Yunnan Normal University, Kunming, P. R. ChInA mailto:wenxian.lin@jcu.edu.au

2. S. W. Armfield, School of Aerospace, Mechanical \& Mechatronic Engineering, The University of Sydney, Sydney, Australia.

3. J. C. Patterson, School of Engineering, James Cook University, Townsville, Australia. 